\title{
Leadership Attitudes and Beliefs of Students Enrolled in an Engineering Lead- ership Course
}

\section{Dr. Kim Graves Wolfinbarger, The University of Oklahoma}

Kim Graves Wolfinbarger directs the Jerry Holmes Engineering Leadership Program at the University of Oklahoma. Her doctoral research explored leadership development among engineering student competition team members. Dr. Wolfinbarger holds a PhD in Industrial \& Systems Engineering, an MS in Industrial Engineering, and a BBA in Marketing, all from Oklahoma.

\section{Dr. Rui (Celia) Pan, Toyota Financial Services}

Dr. Pan is currently working as a sales, product and remarketing analyst at Toyota Financial Servcies, She received her Ph.D in Engineering Education, M.S. in Statistics and B.S. in Electrical Engineering. 


\section{Leadership Attitudes and Beliefs of Students Enrolled in an Engineering Leadership Course}

\section{Introduction}

An engineering leadership development course offered at an American university was originally designed and taught by a retired senior military officer. This course has been taught for almost twenty years and is lauded by graduates as a transformative experience. However, a formal assessment of this course has never been conducted.

The course creator (Instructor A) continues to teach. A new section, taught by an academic researcher with experience in engineering leadership education (Instructor B), was recently added. Although the instructors collaborate, their pedagogical approaches and some of the content in their respective sections differ. The creation of a new version of the course provided an opportunity to conduct a comparative assessment of the course's influence on students' understanding of leadership.

\section{Purpose}

The purpose of this study was two-fold:

1. To evaluate the effects of an engineering leadership course on students' perceptions of leadership, as measured by the Leadership Attitudes and Beliefs Scale (LABSIII), ${ }^{1}$ and

2. To compare the two instructors' sections, with the goal of identifying differential effects of the instructors' approaches.

\section{Background}

Course description. The course examined for this study is taught through a combination of methods, including directed readings, classroom discussions, activities, reflective writing, and presentations by guest speakers. Students in both sections learn about self-management, values, centralized and decentralized organizational structures, the leadership vs. management debate, implicit bias, women in leadership, and creating a culture of participative decision-making. Guest speakers from a range of industries and levels of experience present to both sections and have lunch with students. The students' learning culminates in a team project.

Instructor A's section emphasizes class discussion of the readings and related concepts, with considerable input from the instructor based on extensive personal experience in the military and private sectors. Instructor A requires only one written assignment, a reflective essay on the theme of self-management. While Instructor B also encourages class discussion, Instructor B's section features more use of personal assessment tools, including Bolton's \& Bolton's People Styles ${ }^{2}$ instrument; more leadership and management theory; more frequent reflective writing; and more team-based activities. 
The Leadership Attitudes and Beliefs Scale. The LABS-III instrument was developed for use with college students and measures leadership understanding on two dimensions: Hierarchical Thinking and Systemic Thinking. Hierarchical Thinking "is characterized by a belief that control and authority extend downward in the hierarchy." Systemic Thinking is characterized by the ability "to relate organizational success to the complex interaction of a number of factors." The instrument is based on the Adaptive Challenges Model, ${ }^{3}$ later refined as Ecological Leadership Theory. ${ }^{4}$ This approach advocates systems thinking, collective participation, and a future orientation in the practice of leadership. LABS-III uses a five-point Likert scale, where 1 indicates strong agreement. Each dimension includes 14 items, and the dimensions are independent. Scores for each item on a dimension are summed to obtain the total score for that dimension. Possible scores range from 14 to 70 , with lower scores indicating higher levels of agreement. Scores ranging from 14 to 41 are High, while those from 42 to 70 are Low. ${ }^{1}$

The Systemic Thinking dimension includes such statements as "Individuals need to take initiative to help their organization accomplish its goals;" "Leadership processes involve the participation of all organization members;" "Anticipating the future is one of the most important roles of leadership processes;" and "Successful organizations make continuous learning their highest priority." Statements on the Hierarchical Thinking dimension include "A leader should maintain complete authority;" "The main task of a leader is to make important decisions for the organization;" "Positional leaders deserve credit for the success of an organization;" and "When an organization is in danger of failure, new leaders are needed to fix its problems."

To date, the scale has seen limited use. ${ }^{5,6-9}$ Three of the seven studies were point-in-time examinations ${ }^{6-8}$ some of which compared students at various academic levels. Fischer and colleagues $^{9}$ conducted a longitudinal study of students enrolled at two small liberal-arts institutions offering several short-term leadership certificate programs. Researchers compared students' LABS-III scores at the beginning of the freshman year to their scores at the end of the senior year. Students' agreement with Systemic Thinking tended to increase over the course of their baccalaureate studies, from a freshman average of 28.02 to a senior average of 25.13. Students were less likely to agree with Hierarchical thinking as seniors $(\bar{x}=41.70)$ than as freshmen $(\bar{x}=39.70)$. Those who completed the Professional Development certificate-a program required for students employed in supervisory positions - increased their level of Systemic Thinking to a greater degree than the general student population. Completion of other leadership certificates did not produce a differential effect.

Only one published study ${ }^{5}$ reported the use of LABS-III in the engineering education context, the Engineering Entrepreneurship Program at Pennsylvania State University. Students enrolled in the Entrepreneurial Leadership course took the assessment at the beginning and end of the course; no significant effects were found for either dimension. In addition, the E-SHIP enrollees did not appear to differ from the general student body on either Systemic or Hierarchical Thinking.

\section{Method}

During the first week of the fall semester, students at a large public university in the United States completed a survey containing the LABS-III instrument. Because leadership perceptions can be influenced by a variety of factors other than course enrollment, the survey also requested 
demographic information and included questions about membership and positional leadership in student organizations, military service, and experience living outside the United States. The survey was administered again during the final weeks of the semester. Scores were compared to determine changes in attitudes and beliefs over the course of the semester. The instructors also completed the scale at the beginning of the semester.

\section{Participants}

Thirty-eight participants completed both the pre-course and post-course surveys. Ten participants were enrolled in Instructor A's section; 28 were enrolled in Instructor B's section. All were juniors or seniors majoring in engineering or related disciplines. Nine identified as women and 29 as men. Four participants were from non-U. S. countries and had spent most or all of their pre-collegiate years outside the U. S. Twenty-nine students were members of a registered student organization and/or a social fraternity or sorority; 10 of those students had been officers in one or more organizations. Four participants had achieved the highest rank in the Boy Scouts of America (Eagle Scout) or Girl Scouts USA (Gold Award). Four were current or former members of the U. S. military. Of the American-born students, four had participated in study abroad programs through the university; two more had lived prior to attending college for more than one year outside the U.S.

\section{Results}

The course instructors had similar scores on both scales. On the Hierarchical Thinking scale, Instructor A scored 53 while Instructor B scored 57, indicating that both instructors had a low level of agreement with Hierarchical Thinking. The instructors exhibited strong agreement with Systemic Thinking; Instructor A scored 17 and Instructor B scored 18.

Students entering the course exhibited a wide range of scores on the Hierarchical Thinking dimension, from 22-52. On average, they agreed somewhat with Hierarchical Thinking $(\bar{x}=$ $37.97, \mathrm{SD}=7.55)$. Scores among Instructor A's students ranged from 26 to 52, with a mean of $40.10(\mathrm{SD}=6.87)$. Scores of Instructor B's students ranged from 22 to 50 , with a mean of 37.21 $(\mathrm{SD}=7.75)$. The between-groups difference was not significant $(p=0.306)$. (See Table 1.)

Greater agreement was evident for Systemic Thinking. Overall, scores ranged from 15 to 34, with a mean of 23.16. In Instructor A's section, Systemic Thinking scores ranged from 17 to 27, with a mean of $22.90(\mathrm{SD}=3.57)$. Scores in Instructor B's section ranged from 15 to 34 , with a mean of $23.25(\mathrm{SD}=4.27)$. Again, there was no significant difference between the two sections $(p=0.818)$.

The results suggest that participation in the course increased students' tendency to think systemically. At the end of the semester, students in both sections moved toward greater agreement with Systemic Thinking, decreasing by 2.50 points to an overall mean of 20.66 . The mean score for Instructor A's class decreased by 2.00 points $(t=2.74, d f=9, p=0.023)$ to 20.90, while the mean score for Instructor B's class decreased by 2.68 points $(t=3.87, d f=27, p=$ $0.001)$ to 20.57 . 
The degree of change in Hierarchical Thinking depended on the section. While the post-semester scores did not differ between the two classes $(p=0.862)$, those in Instructor B's class experienced a greater amount of change. Students in Instructor A's class experienced no significant change $(p=0.957)$. Those in Instructor B's class expressed less agreement with Hierarchical Thinking after taking the course; the class average on the Hierarchical scale increased by 2.47 points $(t=-2.11, d f=27, p=0.044)$ to 39.68 .

Table 1. Students' mean scores on the Hierarchical Thinking and Systemic Thinking Dimensions, by course instructor.

\begin{tabular}{|l|r|r|r|r|r|r|}
\hline & \multicolumn{3}{|c|}{ Hierarchical Thinking } & \multicolumn{3}{c|}{ Systemic Thinking } \\
\hline & \multicolumn{1}{|c|}{ Pre } & \multicolumn{1}{|c|}{ Post } & \multicolumn{1}{c|}{ Change } & \multicolumn{1}{c|}{ Pre } & \multicolumn{1}{c|}{ Post } & \multicolumn{1}{c|}{ Change } \\
\hline Overall & 37.97 & 39.76 & 1.79 & 23.16 & 20.66 & -2.50 \\
\hline Instructor A's Class & 40.10 & 40.00 & -0.10 & 22.90 & 20.90 & -2.00 \\
\hline Instructor B's Class & 37.21 & 39.68 & 2.47 & 23.25 & 20.57 & -2.68 \\
\hline
\end{tabular}

Instructors' scores were not correlated with students' post-course scores on either the systemic scale $(p=0.618)$ or the hierarchical scale $(p=0.368)$. Participation in student organizations also had no significant effect on either dimension $(p$-Systemic $=0.075 ; p$-Hierarchical $=0.114)$. The low number of matched respondents prevented meaningful comparisons on the basis of gender, race, country of origin, international living, or military service.

\section{Discussion}

This engineering leadership course was not designed with the Adaptive Challenges Model ${ }^{3}$ or Ecological Leadership Theory ${ }^{4}$ in mind. Instead, the Leadership Attitudes and Beliefs Scale was chosen for the analysis because most of the scale items corresponded to concepts covered in the course. Both of the course instructors prefer decentralized organizational structures and promote the concepts of participative decision-making and leadership at all levels of an organization.

The Systemic views of the course instructors are reflected in the course content. Of the items on the Systemic dimension, only two were not a focus of the course: Item 9, "Organizational actions should improve life for future generations," and Item 23, "Environmental preservation should be a core value of every organization." In contrast, both instructors disagreed or expressed a neutral opinion with most items on the Hierarchical dimension, and many of the concepts discussed in the course were intended to counter hierarchically-oriented thinking. For example, Item 10 states that "The main task of a leader is to make the important decisions for an organization." The instructors of course stressed the opposite - that leaders must foster an environment where all members of the organization can contribute to decision-making, and that one of a leader's main tasks is to instigate change. Regarding Item 15, "It is important that a single leader emerges in a group," Instructor A gave several examples in which — even in a military environment - this might not always be the case. And in Instructor B's course, students engaged in several in-class activities during which some groups accomplished tasks without the designation or emergence of a single leader. The instructors and several of the guest speakers also opposed the notion of giving credit for organizational success to positional leaders (Item 21), instead giving examples 
of situations in which line employees and others were celebrated for their contributions to their organizations.

One hierarchical concept that is promoted in the course is exemplified by Item 27, "Leaders are responsible for the security of organization members." Both instructors agreed with this concept.

\section{Limitations}

As mentioned earlier, leadership perceptions can be influenced by a variety of experiences. It is possible that the changes in LABS-III scores over the semester may be attributable to factors other than course participation. Inclusion of a control group could have strengthened the study. The small sample size prevented meaningful comparisons on most of the measured external factors, with the exception of participation in other university-sponsored student-led organizations. Such participation did not appear to be related to LABS-III scores at either the beginning or end of the study. Furthermore, changes in leadership attitudes probably did not result from maturation effects, given the short period between administration of the first and second surveys. Enrollment in the engineering leadership course was the only known common attribute of all participants; therefore, we are confident that the effects are likely due to course participation.

\section{Conclusion}

Participation in this engineering leadership course appeared to change students' beliefs and attitudes regarding leadership. Students were more likely to think systemically and less likely to think hierarchically after taking the class. And the course was efficient: The change in systemic thinking exhibited over a single semester $(\Delta=-2.50)$ was similar in magnitude to the change experienced by students over four years in the longitudinal study by Fischer and colleagues ${ }^{9}(\Delta=$ $-2.89)$. The change in hierarchical thinking in the present study $(\Delta=1.79)$ was also comparable to that of the Fischer study $(\Delta=2.00)$.

Differences between the sections were notable only on the hierarchical dimension. Instructor A's students' level of hierarchical thinking changed very little, while Instructor B's students experienced a larger shift $(\Delta=2.47)$ away from hierarchical thinking. Recall that the instructors scored similarly to each other on both dimensions, and that the students' scores were not correlated with their instructor's scores. This suggests that the differences in the students' hierarchical scores may be attributable to differences in the instructional approaches. However, the small sample size, particularly from Instructor A's section, limits the power of these results; further data must be collected before we can be confident in drawing a relationship between the instructor's approach and the students' LABS-III scores.

The results presented here reflect data from only one semester. Further evaluation of the course using the LABS-III instrument is scheduled to continue for the next five semesters, through the spring of 2018. Collecting additional data will permit the analysis of the differential effects associated with student organization participation, demographic categories, and international status on students' attitudes and beliefs about leadership. 
High levels of systemic thinking are essential for modern engineering practice. Engineering leaders should be able to consider and evaluate multiple and interrelated aspects of problems and potential solutions, and they should be comfortable with messy, non-positivist approaches. The moderation of hierarchical thinking is also desirable. While some degree of hierarchical thinking is necessary, particularly in respect to safety and legal compliance, engineering leaders should work to foster a culture of decentralized decision-making and leadership at all levels of an organization. A collaborative work environment promotes creativity and encourages a rich approach to framing and solving problems; these skills are less likely to be fostered in an organization that emphasizes deference to a hierarchy. Results from this study are encouraging. Through this course, students decreased their reliance on hierarchical thinking, improved their ability to think systemically, and enhanced their readiness to serve as engineering leaders in a professional setting.

\section{References}

[1] Wielkiewicz, R. M. (2000). The leadership attitudes and beliefs scale: An instrument for evaluating college students' thinking about leadership and organizations. Journal of College Student Development, 41, 3, 335-346.

[2] Bolton, R., \& Bolton, D. G. (2009). People Styles at Work and Beyond, 2nd ed. New York: AMACOM.

[3] Allen, K. E., Stelzner, S. P., Wielkiewicz, R. M. (1998). The ecology of leadership: Adapting to the challenges of a changing world. The Journal of Leadership Studies, 5, 2, 62-82.

[4] Wielkiewicz, R. M., \& Stelzner, S. P. (2005). An ecological perspective on leadership theory, research, and practice. Review of General Psychology, 9, 4, 326-341.

[5] Bilán, S. G., Kisenwether, E. C., Rzasa, S. E., \& Wise, J. C. (2005). Developing and assessing students' entrepreneurial skills and mindset. Journal of Engineering Education, 94, 2, 233-243.

[6] Thompson, M. D. (2006). Student leadership process development: An assessment of contributing college resources. Journal of College Student Development, 47, 3, 343-350.

[7] Thompson, M. D. (2012). Gender differences among contributing leadership development resources. Journal of College Student Development, 53, 3, 472-476.

[8] Wielkiewicz, R. M., \& Fischer, D. V. (2012). Leadership attitudes and beliefs of incoming first-year college students: A multi-institutional study of gender differences. Journal of Leadership Education, 11, 2, 1-25.

[9] Fischer, D. V., Wielkiewicz, R. M., Stelzner, S. P., Overland, M., \& Meuwissen, A. S. (2015). Changes in leadership attitudes and beliefs associated with the college experience: A longitudinal study. Journal of Leadership Education, 14, 4, 14-32. 